\title{
O NEGRO-ABANDONADO NA REPÚBLICA QUE NÃO FOI, POR MEIO DO LITERATURA MACHADIANA
}

\author{
Murilo Chaves Vilarinho ${ }^{1}$
}

\begin{abstract}
RESUMO
O povo brasileiro assistiu bestializado ao alvorecer da República, para José Murilo de Carvalho. Esperou-se que o governo incluísse socialmente os antigos cativos como cidadãos, todavia o abandono tornou-se a realidade desses indivíduos, que, mesmo após a Abolição, não se constituíram como grupo coeso em termos de identidade, segundo Florestan Fernandes. Esta reflexão pretende fazer alguns apontamentos sobre a identidade e a exclusão social do negro na Primeira República. Metodologicamente, empregaram-se pesquisa bibliográfica e análise documental. Alguns textos literários de Machado de Assis foram estudados à luz do Pensamento Social Brasileiro sobre o contexto histórico pós-escravista. Acredita-se, enfim, que os escritos machadianos, fonte de memória, podem descrever o cotidiano dezenovesco, quando o escravo se tornou um liberto e, por conseguinte, um abandonado pela sociedade classista e pelo Estado Nacional.
\end{abstract}

Palavras-chave: Negro-abandonado, Literatura machadiana, Primeira República.

\section{THE ABANDONED AFRICAN IN THE REPUBLIC THAT WAS NOT, THROUGH MACHADIAN LITERATURE}

\begin{abstract}
The Brazilian people watched bestialized at the dawn of the Republic, for José Murilo de Carvalho. The government was expected to socially include former captives as citizens, however abandonment became a reality, which, even after Abolition, they did not constitute a cohesive group in terms of identity, according to Florestan Fernandes. This reflection seeks to make some notes on the identity and social exclusion of former slaves in the First Republic. Methodologically, bibliographic research and documentary analysis were employed. Some literary texts by Machado de Assis were studied in the light of the Brazilian Social Thought on the post-slavery historical context. Finally, it is believed that Machado's writings, a source of memory, can describe the nineteenth-century daily life, when the slave became a freedman and, consequently, abandoned by the classista society and the National State.
\end{abstract}

Keywords: Abandoned African, Machado's Literature, The First Republic.

1 Universidade Federal de Goiás (UFG)

Autor Correspondente: Murilo Chaves Vilarinho

E-mail: murilochv@yahoo.com.br

Recebido em 18 de Junho de 2021 | Aceito em 24 de Janeiro de 2022. 
A Proclamação da República (Fig.1), no Brasil, foi consequência do golpe de 1889, orquestrado, principalmente, por círculos militares, pela elite rural, e recebida pela população da Corte (Rio de Janeiro), de modo aturdido. Evidentemente, o povo bestializado, que se tornou bilontra, assistiu ao alvorecer de uma nova época, ou de uma República que não foi, ou seja, de uma República irreal, que nunca foi uma coisa pública, mas extensão do privado de uma elite da terra, parafraseando José Murilo de Carvalho (1987). Além disso, o ato de abolição da escravatura foi um dos mais significantes petardos para a queda do Império escravista de Pedro II, que conduziu o país rumo à "nova ordem", conforme o entendimento de Oliveira Vianna (2006).

Figura 1 -Proclamação da República

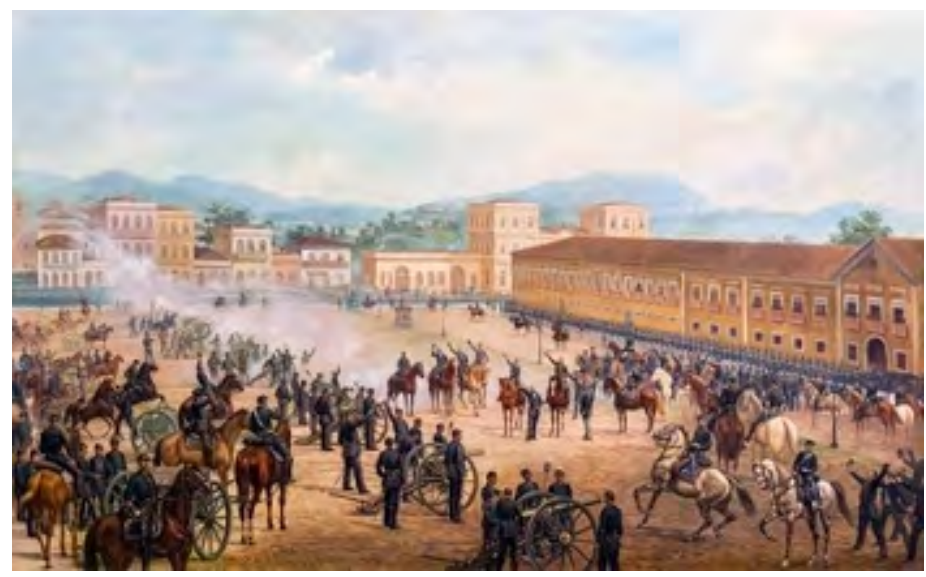

Fonte: Óleo sobre tela de Benedito Calixto (1893). Pinacoteca - São Paulo

No que concerne à Abolição, o Estado nacional brasileiro, no ano de 1888, concedeu, por meio da Lei Áurea, um fato já previsto, dadas as sucessões de leis e pressões internas e internacionais em favor do fim do regime de servidão, fala-se da liberdade aos escravizados; todavia, apesar de estarem libertos, ainda estavam presos à estrutura social escravista e à mentalidade patriarcalista, que ainda no tempo presente, de algum modo, mostram suas faces obscuras. Desse modo, mesmo estando os negros livres da opressão da chibata, não conformaram uma identidade enquanto povo, conforme destaca o pensamento de Florestan Fernandes (1965) o que indubitavelmente fortaleceria o grupo e uma inserção justa e mais equitativa na sociedade da época.

Esperou-se que a Primeira República fosse acolhedora em relação às classes menos abastadas e conferisse a essas, em especial aos negros, o status de cidadania; contudo verificou-se o contrário, isto é, a "população de cor" (termo cunhado por Florestan Fernandes) foi abandonada pelas ordenações públicas, até mesmo pela Igreja, num momento em que os ventos liberais com um tom republicano sopravam de modo efusivo, em favor da antiga possessão lusitana.

Os negros, além de abandonados, foram excluídos da tessitura urbana. A política de reforma urbanística de Pereira Bastos, por exemplo, empurrou, para a periferia da cidade do Rio de Janeiro os antigos escravos, que ali se aglomeraram, oriundos das fazendas, após a promulgação da Lei Áurea, segundo a concepção de Sevcenko (1998). Esse cenário da capital da República indica qual o tipo de conjuntura permeava não só a sociedade brasileira do período, mas também o destino dos negros- a exclusão.

Em face do exposto, almeja-se, de modo geral, pensar a identidade e a exclusão social de parte da população que foi abandonada, na primeira década da Primeira República brasileira, momento em que o negro deveria ter se tornado um grupo étnico coeso ou classe organizada, com a finalidade de estabelecer sua condição e de tê-la respeitada pelo pode estatal e pela sociedade vigente. 
Metodologicamente, o texto é fruto de pesquisa bibliográfica e documental. Além disso, o cenário social e histórico do Brasil à época da Primeira República será pensado com base nas reflexões de intelectuais do Pensamento Social Brasileiro. O universo do negro, por sua vez, será abordado por meio da literatura machadiana, referenciando, em especial, a crônica de 10 de maio de 1894, na qual Machado de Assis, um observador arguto e testemunha dos eventos de sua época, representou o negro no Brasil republicano com riqueza de informações.

Entre os vários trabalhos machadianos, foi escolhida a crônica pelo seu formato textual cotidiano de abordar fatos do momento, de modo crítico e alusivo. A peça literária de 10 de maio apresenta-se como uma das mais nítidas, em se tratando do momento histórico pós-Abolição. Nela, a situação do negro, apesar de caracterizada ficcionalmente, converge para o real em vários aspectos, o que pode ser afiançado pela concepção de Paul Ricoeur (2007) para quem o texto literário é considerado um elemento de memória capaz de revelar as tramas do passado que foi soterrado pelo tempo transcorrido e que pode ser revivido.

A proposta em destaque justifica-se, em termos de significância, pelo fato de contribuir para os debates epistemológico e científico não só da Sociologia da Literatura e do Pensamento Social Brasileiro, mas também da pesquisa que faz uso do texto literário como elemento de memória e documento historiográfico dos mais importantes para se compreender o passado de um povo.

Por fim, o presente artigo divide-se em duas relevantes seções. No primeiro momento, em Da queda do Império de Pedro Il à Proclamação da República no Brasil: identidade, não inclusão e abandono do negro, algumas notas, serão feitos alguns comentários sobre o contexto histórico e social brasileiro, tendo como recortetemporal os momentos finais do Segundo Império e a Primeira República proclamada, evidenciando a figura do ex-escravo nesse novo cenário. Na última seção, O negro abandonado, representado na literatura realista machadiana: uma visita à crônica de 10 de maio de 1894, o texto de Machado de Assis será estudado, com a finalidade de entender a tipologia negro-abandonado, inserido na sociedade de libertos. O literato carioca, um expectador e testemunha do século XIX, por meio da escrita, legou à posteridade seu entendimento e concepção do negro naquele cotidiano de rupturas e mudanças.

\section{DA QUEDA DO IMPÉRIO ESCRAVISTA DE PEDRO II À PROCLAMAÇÃO DA REPÚBLICA NO BRASIL: IDENTIDADE, NÃO INCLUSÃO E ABANDONO DO NEGRO, ALGUMAS NOTAS}

Figura 2- Retratos do regime de servidão: o mercado de escravos

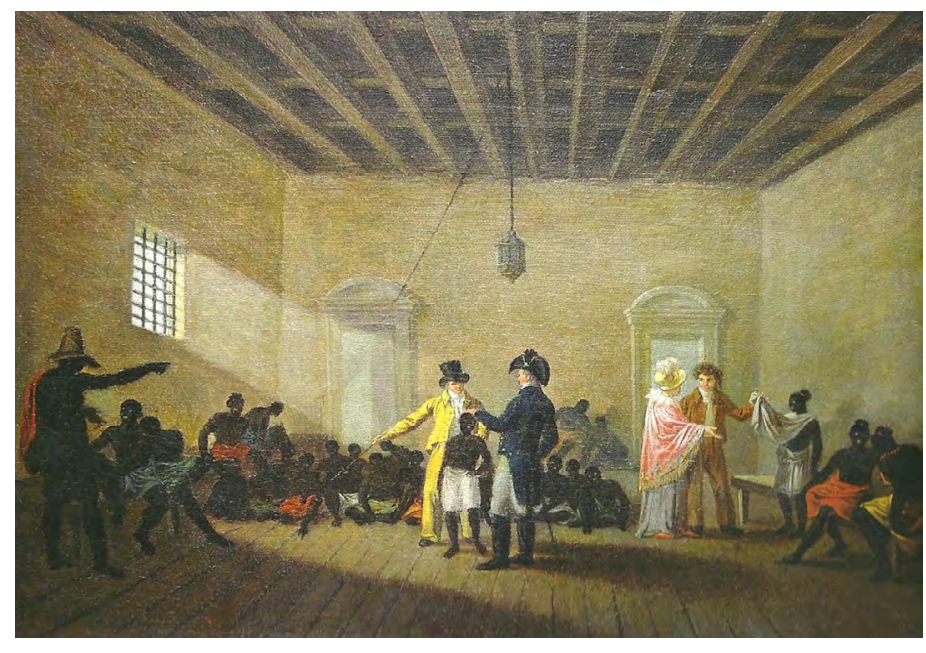

Fonte: Jean Baptiste Debret. Viagem Pitoresca e Histórica ao Brasil. 
O escravo, desde o início da montagem do sistema colonial, sustentou o desenvolvimento e a construção do Brasil, além de ser considerado mercadoria ou animal como apresenta o quadro de Debret (Fig.2) que abre esta seção do texto. Sobre o escravizado, que características o definiam? Gorender (2001, p.47), menciona que "[...] sua pessoa é a propriedade de outro homem, sua vontade está sujeita a autoridade do seu dono e seu trabalho ou serviço são obtidos através da coerção."

Embora esses aspectos caracterizassem o negro e seu dia a dia; em maio de 1888, sua situação, em tese, modificou-se, positivamente; pois era extinta a escravidão no Estado brasileiro, processo que havia conformado séculos de história do país.

O desmonte do sistema escravista foi lento, endossado por uma série de leis de cunho abolicionistas, que gradualmente foram minorando o dinamismo da escravidão. Dessa forma, as Leis Eusébio de Queiroz, Vente Livre, Sexagenários, à medida que eram promulgadas, o comércio que nutria o sistema escravista declinava-se. É evidente que, em curto ou médio prazo, a escravidão perderia espaço para a era moderna, baseada na liberdade e na essência capitalista.

O escravo, ao ser libertado pela Lei Áurea, não deixou de ser escravo para a sociedade branca, porque os anos de cativeiro, de fato, criaram uma imagem do negro em termos de fenótipo, ligado ao atraso, corroborando a manutenção da mentalidade senhorial, eivada pelo preconceito de cor. Além disso, a ingerência e o trabalho braçal são algumas das concepções que permaneceram no imaginário do branco e, por conseguinte, continuaram a caracterizar a "população de cor" no momento posterior à abolição da escravatura.

A Abolição foi, sem dúvida, uma das principais causas da queda do Império de Dom Pedro Il. Apesar de esse ter sido um monarca esclarecido, o sistema agroexportador brasileiro ainda estava habilitado, sendo os braços dos escravos um dos sustentáculos econômicos do país.

Boris Fausto (2010) enuncia que a crise imperial se inicia a partir de 1870. O Movimento Republicano, as divergências entre Igreja, política imperial e Exército foram alguns dos aspectos coadjuvantes da derrocada da Casa dos Bragança; entretanto foi a libertação dos escravos o mais proeminente (VIANNA, 2006).

Essa indicação baseia-se na fala do Barão de Cotegipe, o qual disse a Regente Princesa Isabel que pelo fato de os negros terem sido libertos, o trono fora colocado em xeque (CRUZ, 2016).

Celso Furtado assevera que:

[...] constituindo a escravidão no Brasil a base de um sistema de vida secularmente estabelecido, e caracterizando-se o sistema econômico escravista por uma grande estabilidade estrutural, explica-se facilmente que para o homem que integrava esse sistema a abolição do trabalho servil assumisse as proporções de uma hecatombe social (FURTADO, 2003, p.138).

Considerando-se o pensamento de Furtado (2003) e o discurso do barão, verifica-se a mudança estrutural provocada pelo fim do sistema escravista. Não só a sociedade deixou de ser senhorial, mas também a cultura, a política, as ideologias passaram por transformações. Entre essas transformações, pode-se dizer que a política foi a mais expressiva. Nesse sentido, em 1889, o poderio monárquico era substituído pelo mando militar (republicano).

No que concerne ao Brasil da Primeira República, o Rio de Janeiro era o coração pulsante do país. Todas as atenções estavam concentradas na antiga Corte. O negro, nesse "novo" espaço, nesse "novo" Brasil, parecia não ter lugar, conforme a concepção de José Murilo de Carvalho (1987).

O que ocorria no Rio de Janeiro simbolizava o que também acontecia nas demais porções territoriais do Brasil. Na capital, houve o crescimento da população de escravos livres, advindos das fazendas, das áreas 
cafeicultoras. O mercado do trabalho livre não conseguiu assimilar esse contingente o que, consequentemente, aumentava-o número de desempregados, de pessoas carentes, de indivíduos que se evadiram para o banditismo e similares, de marginalizados, de abandonados pela República, que deveria, em tese, fazer jus ao lema liberdade, igualdade e fraternidade, heranças iluministas, que foram amadurecidas pelo advento da Revolução Francesa.

O abandono do negro pode ser entendido, consoante o pensamento de Florestan Fernandes (1965, p.01):

A desagregação do regime escravocrata e senhorial operou-se, no Brasil, sem que se cercasse a destituição dos antigos agentes de trabalho escravo de assistência e garantias que os protegessem na transição para o sistema de trabalho livre. Os senhores foram eximidos da responsabilidade pela manutenção e segurança dos libertos, sem que o Estado, a Igreja ou outra qualquer instituição assumisse encargos especiais, que tivessem por objeto prepará-los para o novo regime de organização da vida e do trabalho.

Em relação ao negro, os poderes políticos e sociais, no contexto pós-abolicionista, deveriam ter discutido a alocação dos remanescentes da escravidão, mas não fizeram. O Brasil da Primeira República poderia ter inserido a "população de cor" na sociedade de classes, que emergia; contudo, nota-se que essa perspectiva não se tornou uma realidade. Assim sendo, José Murilo de Carvalho (2008, p.52) complementa:

No Brasil, aos libertos não foram dadas nem escolas, nem terras, nem empregos. Passada a euforia da libertação, muitos ex-escravos regressaram a suas fazendas, ou a fazendas vizinhas, para retomar o trabalho por baixo salário. Dezenas de anos após a abolição, os descendentes de escravos ainda viviam nas fazendas, uma vida pouco melhor do que a de seus antepassados escravos. Outros dirigiram-se às cidades, como o Rio de Janeiro, onde foram engrossar a grande parcela da população sem emprego fixo. Onde havia dinamismo econômico provocado pela expansão do café, como em São Paulo, os novos empregos, tanto na agricultura como na indústria, foram ocupados pelos milhares de imigrantes italianos que o governo atraía para o país. Lá, os ex-escravos foram expulsos ou relegados aos trabalhos mais brutos e mais mal pagos.

Em se tratando da inserção do negro na sociedade pós-abolicionista, observa-se, no pensamento do historiador mineiro, que ela começou a ser mitigada e depreciada, quando da promulgação da Constituição de 1891. Sobre esse aspecto,

No que se refere aos direitos civis, pouco foi acrescentado pela Constituição de 1891 . O mesmo se pode dizer dos direitos políticos. As inovações republicanas referentes à franquia eleitoral resumiram-se em eliminar a exigência da renda, mantendo da alfabetização (CARVALHO, 1987, p.43).

Por meio da reflexão de (CARVALHO, 1987) certifica-se que a população de cor, apesar de livre e portadora de "direitos civis", estava, na verdade, excluída da participação política e alijada da cidadania, portanto da própria tessitura social, haja vista que essa não era letrada, um dos requisitos exigidos pelos poderes da administração pública para a participação.

Sobre essa concepção que circunscrevia o negro na Primeira República, nota-se, ainda Carvalho (2008, p.53) que:

Do ponto de vista que aqui nos interessa - a formação do cidadão -, a escravidão afetou tanto o escravo como o senhor. Se o escravo não desenvolvia a consciência de seus direitos civis, o senhor tampouco o fazia. 0 senhor não admitia os direitos dos escravos e exigia privilégios para si próprio. Se um estava abaixo da lei, o outro se considerava acima. A libertação dos escravos não trouxe consigo a igualdade efetiva. Essa igualdade era afirmada nas leis mas negada na prática. Ainda hoje, apesar das leis, aos privilégios e arrogância de poucos correspondem o desfavorecimento e a humilhação de muitos.

Mecanismos de exclusão dos negros, por exemplo, a política do " bota-abaixo," foram empregados. Essa, conformada durante a administração Pereira Bastos, no Rio de Janeiro, desmantelou a habitação da 
população pobre e negra que viviam no centro da capital da nova República e, por consequência, expulsou-a para a periferia da cidade. Os tempos do abandono estavam sendo edificados.

O negro, para Bosi (1992, p.271), “[...] é expulso de um Brasil moderno, cosmético [...]. O senhor liberta-se do escravo e traz ao seu domínio o assalariado [...]." Além disso, Bosi ${ }^{1}$ pontua, de modo substancial que "[...] não se decretava oficialmente o exílio do ex-cativo, mas este passaria a vivê-lo como um estigma na cor da sua pele."

Em termos de identidade do negro, observa-se:

O centro dinâmico da sociedade em formação girará em torno das personagens centrais do fazendeiro e do imigrante, aguçando as dificuldades de ajustamento dos negros, vedando-lhes o acesso aos princípios da socialização emergente. Na base de tal processo, encontram-se o "desajustamento estrutural" e a "desorganização social" típicos da condição de negros e mulatos, não se operando a reclassificação no âmbito da sociedade. A vivência dos estados de anomia e heteronímia, por parte desse contingente de marginalizados, diluíram a construção da nova identidade que em última instância sequer se forma (ARRUDA, 1996, p.197).

Em suma, o negro, após abolição, apesar de ser livre, teve o preconceito de cor conservado, perante a mentalidade senhorial, que ainda se propagava na contextura social dezenovesca e imperial, em vias de transformação republicana.

A Proclamação de 1889, liderada por Deodoro da Fonseca, apoiada por setores proeminentes do Brasil, colocou em xeque a inclusão da população liberta. Esses não se inseriram na sociedade de classes nascente. O abandono, por conseguinte, tornou-se a nova realidade do negro em uma nação republicana, que não contemplara democracia racial, como defendia Freyre (1994), por exemplo.

Se a população negra tivesse conformado uma identidade forte, coesa, organizada, pautada pelo ideário de uma raça, mesmo que miscigenada, e por um ethos cultural, em contraposição à vivência de alguns estados depreciativos, sublinhados por Arruda (1996), talvez sua condição tivesse sido diferente, já que teria condições de mobilizar-se, em face da sua situação de marginalização, de abandono.

\section{3. $O$ NEGRO ABANDONADO, REPRESENTADO NA LITERATURA REALISTA MACHADIANA: UMA VISITA À CRÔNICA DE 10 DE MAIO DE 1894}

Ricoeur (2007) anuncia que o texto literário é fonte de memória, capaz de informar sobre o ter-sido. O passado é resguardado nas entrelinhas do escrito, o qual, ao ser lido, por meio de uma operação hermenêutica, é capaz de refratar entendimentos sobre Outro, sobre sua vida.

A literatura não necessariamente é o mero reflexo da realidade social como muitos imaginam. Eagleton (1978, p.68) acredita que:

A literatura poderia então dizer-se, não está numa relação reflexiva, simétrica, unívoca, para com o seu objeto (a realidade social). O objeto é deformado, refratado, dissolvido - reproduzido não tanto no sentido em que um espelho reproduz o seu objeto, mas, talvez, mais como uma representação teatral reproduz o texto dramático [...] a representação teatral é, manifestamente, mais do que um reflexo do texto dramático; pelo contrário [...] é uma transformação do texto num produto com características únicas, o que implica a sua reelaboração de acordo com as exigências e condições específicas da representação teatral [...].

O texto literário evidencia, de modos reelaborado e crítico, uma sociedade, e representa, por exemplo,

$1 \mathrm{Idem}$ 
seus indivíduos, por meio de personagens. Essa representação não apenas reflete o cotidiano, mas também destaca os aspectos mais prementes de um grupo, em termos de comportamento, de mentalidade (VILARINHO, 2017; 2019; 2020). Em suma, a literatura machadiana, material empírico, é capaz retratar rotina da sociedade brasileira à época da transição entre Império-República.

Machado de Assis (Fig. 3), escritor carioca dezenovesco, foi expectador de seu tempo, falou sobre o Rio de Janeiro, sobre o Brasil e sobre seus acontecimentos mais marcantes (PEREIRA, 1988).

Figura 3- Machado de Assis

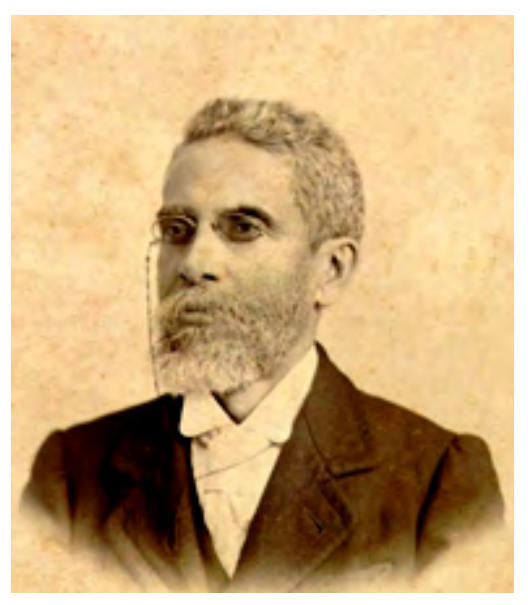

Fonte: $\mathrm{ABL}$

Abolição da escravatura, a Proclamação da República, segundo Pereira (1988), foram temas de sua produção, de suas críticas e de sua fina ironia. Nesse sentido, romances, crônicas e contos revelavam o tom arguto e perspicaz do literato em refletir a vida dezenovesca brasileira.

A situação árdua do negro não passou despercebida ao olhar do escritor Machado de Assis, embora muitos o apontem como um indivíduo que não foi homem de seu tempo e de seu país, isto é, não se comprometera, de modo dinâmico e político, com os assuntos que reclamavam mobilização social.

Machado de Assis fez uso da escrita, da pena e da imaginação, com a finalidade de expor, ao seu modo literário- realista, o que, de fato, ocorria na sociedade senhorial, segundo destaca o entendimento de Vilarinho (2012; 2019; 2020).

Entre a vastíssima bibliografia machadiana, as crônicas apresentam-se como relevantes, para se ilustrar a contextura social da qual foi contemporâneo, pois uma das características dessa natureza textual é lidar com fatos diários de maneira crítica, humorística e leve (CANDIDO, 1992).

Em se tratando do negro abandonado, ressalta-se a história de uma crônica, em especial, publicada em $A$ Semana (10/06/1894), portanto no início da Primeira República. Nessa narrativa, Machado de Assis faz uso da personagem burro, referindo-se ao antigo escravo, vivendo uma nova contextura social. Além disso, o ano de publicação da crônica mostra a temporalidade que marca alguns anos, depois do advento da Proclamação.

O escrito, um tipo de fábula, fala, em geral, sobre um burro, Lucius de Tessália, que entra em um jardim, é surpreendido pelo dono do lugar e, em seguida, iniciam um interessante diálogo, cujo desfecho é o pedido de ajuda ao cronista para que ele o ajude e aos seus junto à imprensa carioca, denunciando a situação de sua classe. Esse burro com características humanas é a personagem que representa o negro. Em suma, nessa crônica, fica evidente a perspectiva da reivindicação ao direito da liberdade, o abandono do negro, pós-abolição. 
Vendo o burro naquele lugar, lembrei-me de Lucius, ou Lucius da Tessália, que, só com mastigar algumas rosas, passou outra vez de burro a gente. Estremeci, e, - confesso a minha ingratidão, - foi menos pela perda das rosas, que pelo terror do prodígio. Hipócrita, como me cumpria ser, saudei o burro com grandes reverências, e chamei-Ihe Lucius. Ele abanou as orelhas, e retorquiu:

- Não me chamo Lucius.

Fiquei sem pinga de sangue; mas para não agravá-lo com demonstrações de espanto, que lhe seriam duras, disse:

— Não? Então o nome de Vossa Senhoria...?

— Também não tenho senhoria. Nomes só se dão a cavalos, e quase exclusivamente a cavalos de corrida [...] (ASSIS, 1997, p.610).

A personagem (burro), ao ser questionada por seu interlocutor, sobre qual seria sua senhoria, no sentido de nome, responde-lhe, diretamente, que não tinha senhoria; e que nomes apenas cavalos de raça os teriam.

É possível depreender desse excerto que Machado de Assis queria expor que o negro não tinha nome, não tinha identidade, não tinha cidadania, não era pessoa que merecesse um nome, tal como percebido pela sociedade senhorial, configurando um dos aspectos de seu abandono. Além disso, quando a personagem diz que somente cavalos de raça têm nomes, seguramente estaria referindo-se ao homem branco, dono de terras, portador de títulos.

Por ser uma crônica escrita em 1894, portanto na primeira década da República, é nítido que a situação do ex-escravo ainda estava em xeque, ou seja, nem com a Abolição ou mudança de ordem política, seus direitos a igualdade, quiçá liberdade foram respeitados. A crítica do escritor carioca está exposta, veementemente, já, no início de seu escrito.

O diálogo prossegue entusiástico. O burro fala ao seu interlocutor sobre a forma com que são tratados e como isso é enquadrado legalmente, por exemplo, na Inglaterra, diferentemente do Brasil. Em Londres, maus tratos desferidos contra os animais são puníveis. Pagam-se indenização pouca, mas pelo menos pagam, já que no Brasil, nada pagam. No diálogo com dono do jardim, o burro enumera inúmeros casos, finalizando com o caso de um senhor que maltratou quatro vacas, devendo pagar cinco libras e custas (ASSIS, 1997, p.611).

Parece que, mesmo com a República, nada havia mudada para os escravos. Em alguma medida, a essência do cativeiro perseguia os libertos, que também não se esqueciam da condição subalterna que vivenciaram em tempos dantes a Lei Áurea. A situação dos negros fica evidente nas palavras que se seguem:

[...] Apanhamos, é verdade, apanhamos de chicote, de ponta de pé, de ponta de rédea, de ponta de ferro, mas é só quando as poucas forças não acodem ao desejo; os burros modernos, esses são teimosos, resistem mais à pancadaria. Afinal, são moços (ASSIS, 1997, p. 612).

Ao final da crônica, verifica-se a parte mais importante da narrativa, quando o burro exorta ao senhor dono do jardim que não o abandone, nem ao seu grupo, como nos tempos em que os burros eram parceiros dos escravos, ou seja, antes da Lei Áurea. Sem dúvida, aqui, Machado de Assis está fazendo uma associação à Abolição, quando ao negro foi dada a liberdade, contudo uma liberdade que não conduziu à participação, à cidadania, à inclusão, à igualdade social, o que se configuraram, na verdade, foram os primeiros passos rumo ao abandono, uma vez que deixaram de ser mão de obra servil, portanto não mais necessários ao sistema. Além disso, é notável o pedido do burro ao senhor, quando aquele sugere que este utilize da imprensa para denunciar a condição dos burros, estruturando-se quase que um movimento popular pela causa de um gru- 
po- os negros. Ao final da narrativa, o animal pede para que o proprietário do jardim faça o Treze de Maio dos ex-escravos, proclame a liberdade, de fato, desses indivíduos, que o senhor seja como Lincoln brasileiro, que conceba, em suma, que os negros sejam iguais aos brancos, em termos de evolução das espécies. $O$ excerto que se segue dispõe dos aspectos apresentados. Assim sendo:

O senhor afinal é da espécie humana, há de defender os seus. Eia, fale aos amigos da imprensa; ponha-se à frente de um grande movimento popular. O conselho municipal vai levantar um empréstimo, não? Diga-lhe que, se lançar uma pena pecuniária sobre os que maltratam burros, cobrirá cinco ou seis vezes o empréstimo, sem pagar juros, e ainda Ihe sobrará dinheiro para o Teatro Municipal, e para teatros paroquiais, se quiser. Ainda uma vez, respeitável senhor, cuide um pouco de nós. Foram os homens que descobriram que nós éramos seus tios, senão diretos, por afinidade. Pois, meu caro sobrinho, é tempo de reconstituir a família. Não nos abandone, como no tempo em que os burros eram parceiros dos escravos. Faça o nosso treze de Maio. Lincoln dos teus maiores, segundo o evangelho de Darwin, expede a proclamação da nossa liberdade! (ASSIS, 1997, p.613).

O que fica é que o pedido do ao senhor do jardim delineia a questão do abandono do ex-escravo em relação ao Estado e à sociedade. A crônica dialoga com o entendimento de estudiosos demiurgos do pensamento social brasileiro (Florestan Fernandes, José Murilo de Carvalho, por exemplo.) que acreditam na exclusão e no abandono da população de cor pelos poderes públicos da República, quando esses indivíduos advindos do cativeiro mais necessitavam de auxílio para se integrarem.

A literatura machadiana, que refletiu o cotidiano social do Rio de Janeiro dezenovesco, de modo realista, permite ao leitor o acesso ao ter-sido de um grupo marginalizado e abandonado. $O$ texto do literato apresenta-se como um rico elemento de memória capaz de representar a vida do negro em profundidade (VILARINHO, 2012; 2014).

\section{4. À GUISA DE CONCLUSÃO}

Apesar de Machado de Assis não ter defendido, explicitamente, o negro, assim como Castro Alves ou José do Patrocínio o fizeram, sua literatura pode ser considerada fonte de pesquisa capaz de auxiliar a compreensão da condição do negro escravizado no século XIX, bem como do abandonado, no Brasil, da República que não foi. A vida, em sociedade, foi refletida, de modo realista, pelo escritor em suas obras. No mais, a árdua situação da "população de cor" não passou despercebida.

A abolição de 1888, apesar de positiva em termos de libertação, não legou aos escravos a inclusão social. Esses foram abandonados à própria sorte. Pensou-se que a República iria modificar o perfil do antigo cativo, mas sua Constituição, por exemplo, assinalou, de uma vez por todas, o abandono da população de cor.

Os negros deveriam ter-se organizados, de modo coeso, enquanto classe, identidade, porém não se estabeleceram nesses termos. Infelizmente, foram relegados ao descaso e à marginalização, quer seja pela raça, pela seja pelo estabelecimento da condição de subalternidade, advindo da mentalidade senhorial centenária.

A reflexão sobre o negro na Primeira República, visitando a expressiva crônica de 10 de junho de 1894, em que o abandono e a incompletude do Treze de Maio são evidenciados, apresenta-se como abordagem importante para a Sociologia, para a História, para a Antropologia entre outros ciências do espírito, pois sua história ainda está sendo escrita e sua inserção social ainda não foi equacionada em sua totalidade. A sociedade brasileira deve a esses indivíduos consideração e reconhecimento, pois foram eles uma das engrenagens que corroboraram a construção de uma nação chamada Brasil. 


\section{REFERÊNCIAS BIBLIOGRÁFICAS}

ACADEMIA BRASILEIRA DE LETRAS. (2019). Machado de Assis. Recuperado de http://www.academia.org.br/abl_minisites/media/ ma_iconografia3.jpg.

ARRUDA, Maria Arminda do Nascimento. (1996). Dilemas do Brasil moderno: a questão racial na obra de Florestan Fernandes. In: MAIO, Marcos Chor \& VENTURA, Ricardo (orgs.). Raça, Ciência e Sociedade. Rio de Janeiro, Ed. Fiocruz.

ASSIS, Machado de. (1997) Gazeta de Notícias, Rio de Janeiro, 10 jun. 1894. "A Semana!”. In: COUTINHO, Afrânio (Org.). Obra completa. (pp.610-613). Rio de Janeiro: Nova Aguilar.

BOSI, Alfredo. (1992). Dialética da colonização. São Paulo: Companhia das Letras.

CANDIDO, Antonio. (1992). A vida ao rés-do-chão. In et. al. Crônica: o gênero, sua fixação e suas transformações no Brasil. Campinas, SP: Editora da UNICAMP; (pp.13-22). Rio de Janeiro: Fundação Casa de Rui Barbosa.

CARVALHO, José Murilo de. Os bestializados: o Rio Janeiro e a República que não foi. São Paulo: Companhia das Letras, 1987.

CARVALHO, José Murilo de. (2008). Cidadania no Brasil. Rio de Janeiro: Civilização Brasileira.

CRUZ, Antonyo Comendador. (2019) Dona Isabel do Brasil, a Redentora. Recuperado de http://www.brasilimperial.org.br/layout/ layout2.php?cdConteudo $=200 \&$ codigo $=34$ :

DEBRET, Jean Baptiste, 1768-1848. (1989). Viagem Pitoresca e Histórica ao Brasil. Tradução: Sérgio Milliet. Belo Horizonte: Ed. Itatiaia Limita da; São Paulo: Ed. da Universidade de São Paulo, (Reconquista do Brasil 3 série especial; vols.10,11 e 12).

EAGLETON, Terry. (1978). Marxismo e crítica literária. São Paulo: USP.

FAUSTO, Boris. (2010). História Concisa do Brasil. São Paulo: EDUSP/Imprensa Oficial.

FERNANDES, Florestan. (1965). A Integração do Negro na Sociedade de Classes. Vol2. São Paulo: Ática.

FREYRE, Gilberto. (1994). Casa Grande \& Senzala. Rio de Janeiro: Record.

FURTADO, C. Formação Econômica do Brasil. 32. ed. São Paulo, SP: Companhia Editora Nacional, 2003.

GLEDSON, John. (2003). Machado de Assis: ficção e história. 2. ed. São Paulo: Paz e Terra.

GLEDSON, John. (2008) Bons dias! Machado de Assis; introdução e notas. Campinas: Editora da Unicamp.

GORENDER, Jacob. (2001). O Escravismo Colonial. 6a ed. São Paulo: Ática.

PEREIRA, Lucia Miguel. (1988). Machado de Assis: estudo crítico e bibliográfico. Belo Horizonte; Itatiaia; São Paulo: Editora da Universidade de São Paulo.

RICOEUR, Paul. (2007). A memória, a história, o esquecimento. Campinas, SP: Editora da Unicamp.

SANTOS, Ricardo Ventura. (1996). Raça, ciência e sociedade. Rio de Janeiro, FIOCRUZ-CCBB.

SEVCENKO, Nicolau (org). (1998). História da Vida Privada Brasileira - volume 3. São Paulo: Cia. das Letras.

VIANNA, Oliveira. O ocaso do Império. (2006). Rio de Janeiro: ABL.

VILARINHO, Murilo Chaves. (2012). O olhar machadiano sobre o cativo: a literatura como importante fonte de conhecimento da oitocentista sociedade escravista carioca. Composição: Revista de Ciências Sociais da Universidade Federal de Mato Grosso do Sul, v. 1, p. 135-148.

VILARINHO, Murilo Chaves. (2014). O mundo do texto na hermenêutica de Paul Ricoeur: um breve estudo sobre as narrativas ficcional e histórica nos trabalhos do literato Machado de Assis e do historiador Sidney Chalhoub. Revista de História (Salvador), v. 5, p. 359-179. 
VILARINHO, Murilo Chaves. (2017). Literatura machadiana: um dos patrimônios culturais do Brasil e elemento de memória da população negra oitocentista. Revista Mosaico - Revista de História, Goiânia, v. 9, n. 2, p. 228-234, maio 2017. ISSN $1983-7801$. Recuperado de http://seer.pucgoias.edu.br/index.php/mosaico/article/view/5037.

VILARINHO, Murilo Chaves. (2019) Algumas reflexões sobre o texto literário: elemento de representação da memória, aspecto para a conformação de estudos sociológicos da literatura. Mosaico: Revista de História, Goiânia, v. 12, p. 188-194.

VILARINHO, Murilo Chaves. Literatura machadiana: patrimônio cultural que expressa a dinâmica social e dimensão imaterial de um povo. (2020). Revista Fragmentos de Cultura - Revista Interdisciplinar de Ciências Humanas, Goiânia, v. 30, n. 1, p. 105-115, nov. 2020. ISSN 1983-7828. Recuperado de http://seer.pucgoias.edu.br/index.php/fragmentos/article/view/7587. 